\title{
Experimental Studies of Drilling Tools Magnetic Catchers with the Parallel Connection of Permanent Magnets
}

\author{
Mikhail. Kobylyansky ${ }^{1}$, Aleksey Ermolaev ${ }^{2}$, Dmitriy Kobylyansky ${ }^{1}$ \\ ${ }^{1}$ T. F. Gorbachev Kuzbass State Technical University, Kemerovo, the Russian Federation \\ ${ }^{2}$ JSC NC VostNII industrial and environmental safety, Kemerovo, the Russian Federation
}

\begin{abstract}
The article presents the results of bench and industrial tests of drilling tools magnetic catchers with the parallel connection of permanent magnets. The catchers are developed on the basis of optimization studies of the mathematical model of the U-shaped magnetic system. The catchers on ferrite-barium magnets with U-shaped magnetic systems showed very low characteristics. The catcher with unshielded magnetic system also showed low power and magnetic parameters. Production tests of such a catcher in a real iron ore well demonstrated its unsuitability for the extraction of the drilling tool elements. Laboratory studies of a magnetic catcher with the shielded U-shaped magnetic system on powerful rare earth magnets have shown that it has high power and magnetic parameters. Its industrial tests in the mine showed high efficiency of the extraction of the drilling tool broken off elements, in particular, crowns and pneumatic hammers. A catcher with the parallel connection of rare-earth magnets with step-shaped magnetic cores was also studied. It has even higher characteristics. The use of step magnetic cores allows to reduce the consumption of magnetic materials by a third. The best results were shown by a catcher with a quadruply connected magnetic system made according to the cruciform configuration on rare earth magnets. The results of the experimental studies well agree with the calculated data, the difference is $10-20 \%$.
\end{abstract}

\section{Introduction}

Optimization studies of the mathematical model of magnetic systems with the parallel connection of magnets have shown that they can be used as the basis for creation a sufficiently effective magnetic catcher $[1,2,3]$. In order to experimentally confirm the results of theoretical developments, a number of designs of magnetic catchers on ferritebarium and rare-earth magnets have been designed, manufactured and studied $[4,5]$.

The LPM-2 catcher with the unshielded magnetic system has been developed and investigated (Fig.1). The parameters of the catcher are shown in Table.1.

As the studies have shown, the maximum force of attraction of the LMP-2 catcher to the test plate was $2.90 \mathrm{kN}$ (the difference from the estimated force of attraction is $5.9 \%$ ). Traction characteristics of the catcher are shown in Fig.2. As it is seen, the retention and 
lifting of the drill bit by the catcher is possible at gaps of no more than $2 \mathrm{~mm}$. The mechanical efficiency does not exceed $0.13[6,7,8]$.

Magnetic catcher LMP-2 was tested in production conditions at the mine of Tashtagol mine group. The tests have shown that the catcher with unshielded U-shaped magnetic system is not operational in iron ore wells. As a result of the shunting action of the walls of the well and the drilling stuff $[9,10,11]$, that clung to the catcher, its force of the attraction fell so much that it was not possible to extract any of the drilling tool elements from the well, except for hard alloy plates.
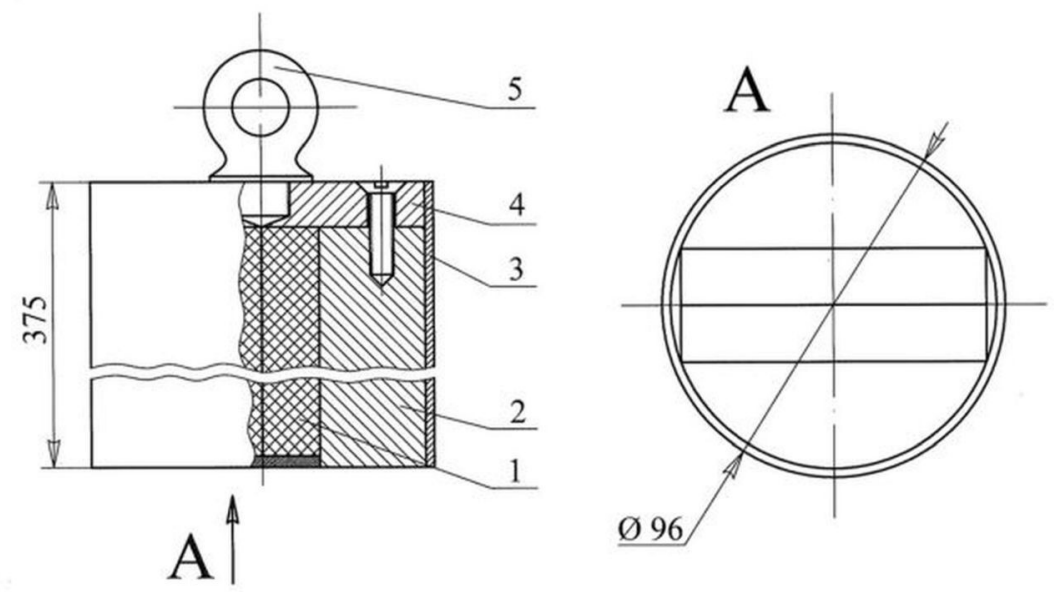

Fig.1. Magnet catcher LMP-2: 1 - permanent magnets 18БА220; 2 -magnetic core; 3 -non-magnetic body frame; 4 -non-magnetic washer; 5 - eye-bolt.

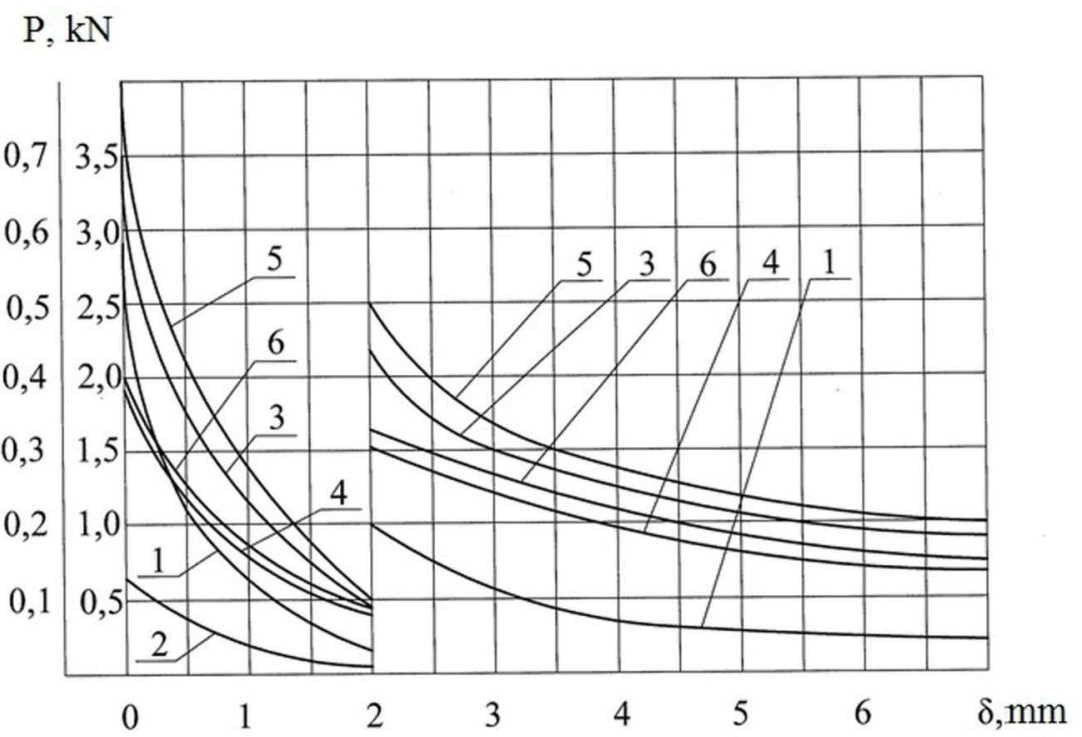

Fig. 2. Traction characteristics of catchers: 1 - when the catcher LMP-2 is attracted to the test plate; 2 - the same to the drill bit; 3 - when the catcher LMP-3 is attracted to the test plate; 4 - the same to the drill bit; 5 and 6 - when the catcher LMP- 3 without a body frame shield to the test plate and the drill bit.

Magnetic catcher LMP-3 with a shielded U-shaped system on rare earth magnets, which showed the best power and magnetic characteristics for this type of catchers, is shown in 
Fig.3. The catcher is made on the magnets from $\mathrm{SmCo} 5$ alloy with the size $50 \times 50 \times 10 \mathrm{~mm}$. The parameters of the catcher LMP-3 are given in Table.1.

Magnetic catcher LMP-3 showed a maximum force of attraction to the test plate 3,40 $\mathrm{kN}$ (the difference from the estimated force of attraction is $4,6 \% /$ ), to the drill bit type KNSh-105 with a broken shank - $1,80 \mathrm{kN}$. Traction characteristics of the catcher are shown in Fig.2.
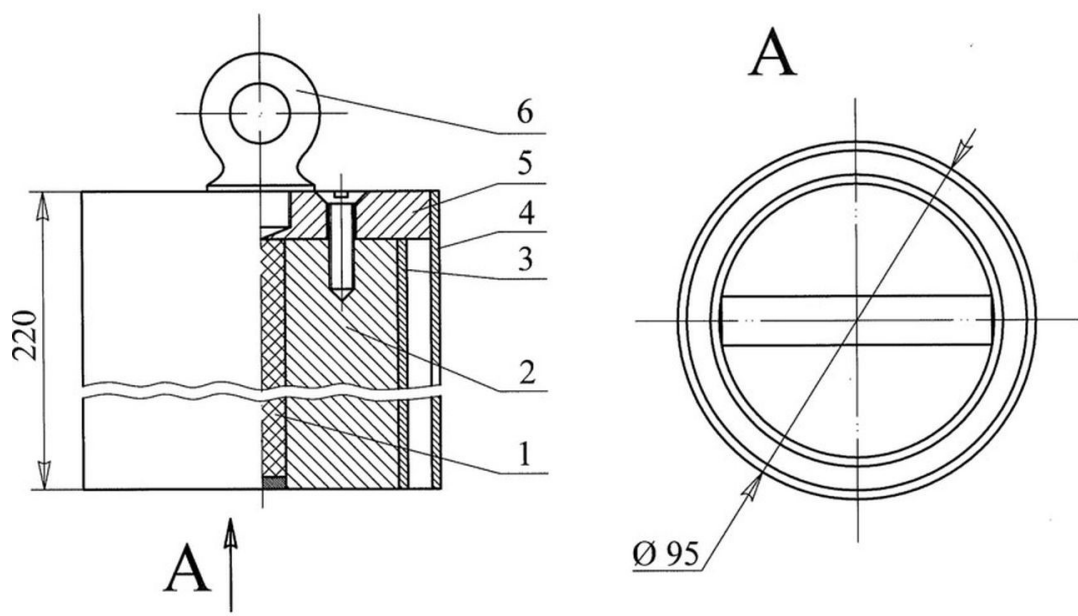

Fig.3. Magnet catcher LMP-3: 1 - permanent magnets $\mathrm{SmCo}_{5} ; 2$-magnetic core; 3 - sleeve; 4 -body frame - shield; 5 - washer; 6 - eye-bolt.

The drill bit is held by the poles of the catcher at gaps up to $6 \mathrm{~mm}$. It is necessary to note the high average value of the specific attraction per unit area of the poles $\left(176 \mathrm{~N} / \mathrm{cm}^{2}\right)$, close to the state of the poles magnetic saturation of steel St.3.

In order to determine the negative impact of the shielding body frame on the parameters of the U-shaped magnetic system on rare earth magnets, the traction characteristics of the LMP-3 catcher without the body frame were fixed (the curves 5 and 6 in Fig.2). As can be seen from the graph, the maximum force of attraction increased up to $3.8 \mathrm{kN}$, the force of attraction to the drill bit - up to $2.0 \mathrm{kN}$. The energy of the catcher increased by $22 \%$.

Magnetic catcher LMP-3 was tested at the mine of Tashtagol mine group. The catcher demonstrated high efficiency and reliability of drill bits, air hammers, hard alloy plates, as well as foreign metal objects extraction from explosive iron ore wells. The catcher has a 60fold reserve on the force of attraction to the drill bit, which allows to reliably extract it in difficult conditions (jamming in the well, slagging of the face, etc.). The steel body frame shields the U-shaped magnetic system and eliminates the negative impact of the external conditions of the drill hole [12].

In order to increase the efficiency of cross-sectional area of the magnetic cores usage the magnetic catcher LMP-4 with a stepped shape of the magnetic cores and magnets was prepared and investigated (see Fig.4).

The catcher LMP-4 contains three permanent magnet $\mathrm{SmCo}_{5}$ with the size $50 \times 50 \times 15$ $\mathrm{mm}$, placed between the magnetic cores of variable cross section. The catcher is enclosed in a steel body frame - shield.

The maximum force of the catcher attraction to the test plate was $3.1 \mathrm{kN}$. That to the drill bit of the type KNSh-105 was $1.8 \mathrm{kN}$. The traction characteristics of the catcher are shown in Fig. 5. The parameters of the catcher are given in Table 1. 

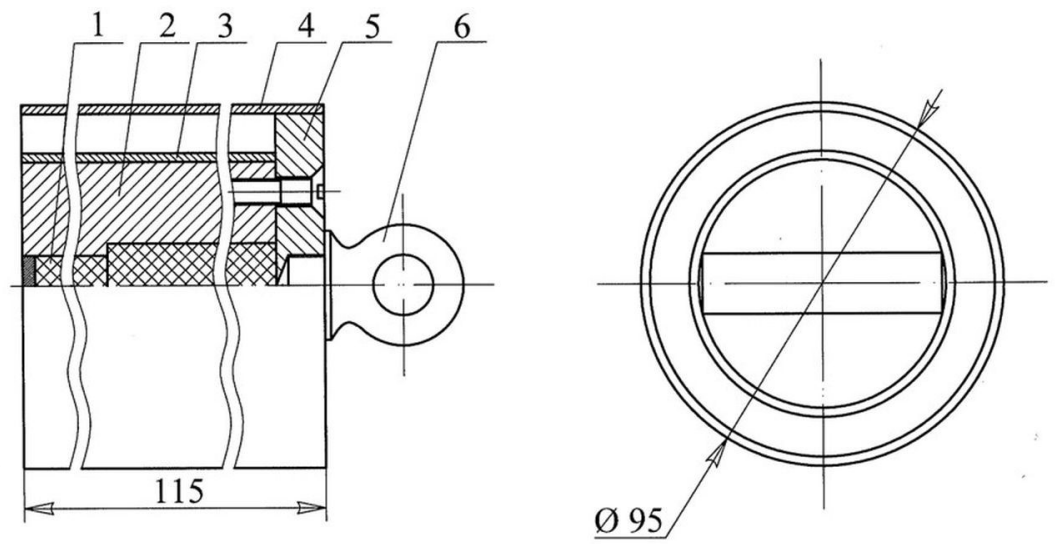

Fig. 4. Magnetic catcher LMP-4: 1 -permanent magnets SmCo5; 2 - stepped shape magnetic core; 3 aluminum shell; 4 - body frame - shield; 5 - non-magnetic washer; 6 - eye-bolt.

\section{$\mathrm{P}, \mathrm{kN}$}

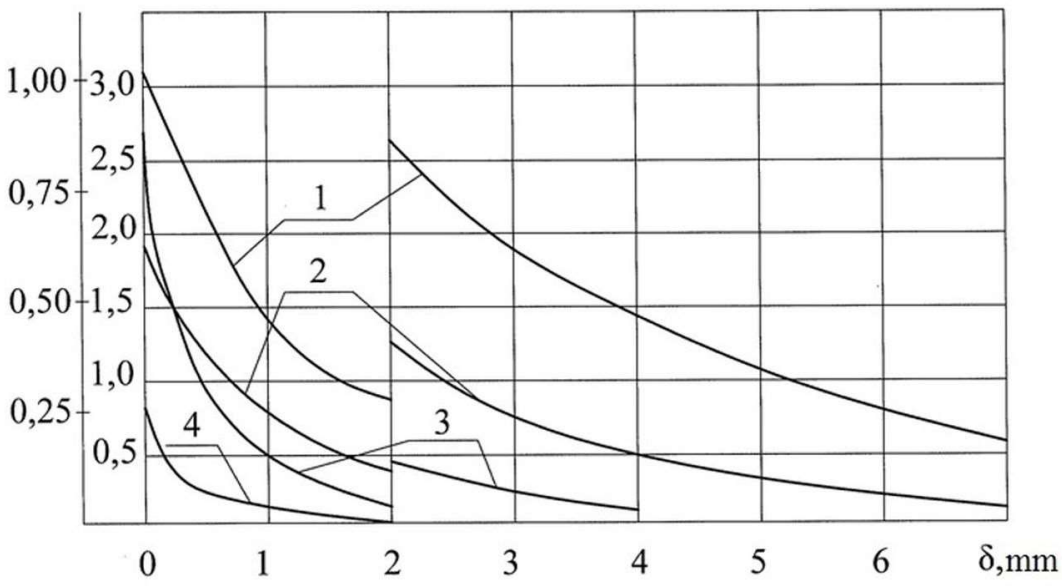

Fig. 5. Traction characteristics of the catchers: 1,2 - when the catcher LMP-4 is attracted to the test plate and to the drill bit; 3, 4 - when the catcher LMP-5 without the body frame - shield is attracted to the test plate and to the drill bit

It should be noted that the LMP-4 catcher has gently sloping nature of the traction characteristics. Thus, with a gap of $2 \mathrm{~mm}$, the force of attraction to the test plate exceeds the same parameter of the LMP-3 catcher by 1.9 times, to the drill bit KNSh-105 - by 2.5 times. One of the main indicators of the magnetic catcher quality - the energy of attraction to the test plate is higher by 1.8 times, to the drill bit - by 1.5 times. Thus, the effect of magnetic cores and magnets of variable cross-section use was experimentally confirmed.

The magnetic catcher LMP-5 with quadruply connected magnetic system was also developed and tested (Fig. 6). The catcher is made according to the cruciform configuration on eight rare-earth magnets $\mathrm{SmCo}_{5}, 30 \times 30 \times 5 \mathrm{~mm}$ in size, located between four magnetic cores made of steel St.3. This arrangement allows to have four opposite poles on the working end of the catcher, which facilitates the capture of metal objects of different shapes. 
As the studies have shown, the screen has a strong shunt effect on the system. In this case, the force of attraction of the cruciform magnetic system falls by several times and does not exceed $100 \mathrm{~N}$. This is due to the large surface area of the unlike magnetized magnetic cores, which creates excessively large scattering flows [13, 14]. Thus, this arrangement is not suitable for use in magnetic catchers, but can be used in lifting devices in other fields of technology. Traction characteristics of the LMP-5 catcher without the shielding body frame are shown in Fig.5, the parameters of the catcher - in Table.1.
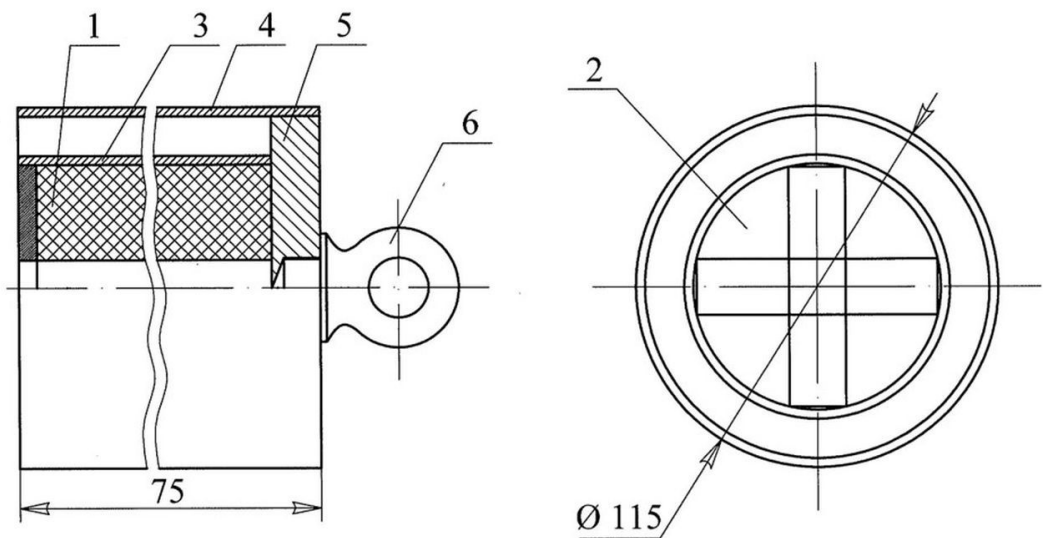

Fig. 6. Magnetic catcher LMP-5: 1 - permanent magnets SmCos; 2 - magnetic core; 3 - aluminum shell; 4 -body frame - shield; 5 - non-magnetic washer; 6 - eye-bolt.

Table 1. Parameters of the catchers with the parallel connection of permanent magnets.

\begin{tabular}{|c|c|c|c|c|c|c|c|c|}
\hline $\begin{array}{c}\text { Type } \\
\text { of a } \\
\text { catcher }\end{array}$ & $\begin{array}{c}\text { Force } \\
\text { of } \\
\text { attracti } \\
\text { onto } \\
\text { the test } \\
\text { plate/ } \\
\text { drill } \\
\text { bit, } \mathrm{kN}\end{array}$ & $\begin{array}{c}\text { Energy } \\
\text { when } \\
\text { attracted } \\
\text { to the } \\
\text { test } \\
\text { plate/ } \\
\text { drill bit, } \\
\mathrm{J}\end{array}$ & $\begin{array}{c}\text { Poles } \\
\text { area, } \\
\mathrm{sm}^{2}\end{array}$ & $\begin{array}{c}\text { Average } \\
\text { specific } \\
\text { attractio } \\
\mathrm{n} \text { force } \\
\mathrm{N} / \mathrm{sm}^{2}\end{array}$ & $\begin{array}{c}\text { Mass } \\
\text { of, } \\
\mathrm{kg}\end{array}$ & $\begin{array}{c}\text { Maximum } \\
/ \\
\text { medium } \\
\text { value of } \\
\text { induction } \\
\text { at the } \\
\text { poles at } \\
\text { zero gap, } \\
\text { mT }\end{array}$ & $\begin{array}{c}\text { Medium } \\
\text { value of } \\
\text { inductio } \\
\text { n in the } \\
\text { working } \\
\text { gap, mT }\end{array}$ & $\begin{array}{c}\text { Mechani } \\
\text { cal } \\
\text { efficienc } \\
\mathrm{y}\end{array}$ \\
\hline $\begin{array}{c}2.9 / 0.6 \\
4\end{array}$ & $\begin{array}{c}1.65 / 0.3 \\
9\end{array}$ & 23.1 & 125.5 & 13.0 & $125 / 58$ & 1.76 & 0.13 \\
\hline $\begin{array}{c}\text { LMP-3 } \\
3.4 / 1.8\end{array}$ & $\begin{array}{c}2.7 / 1.80 \\
0\end{array}$ & 19.3 & 176.0 & 7.0 & $450 / 210$ & 2.08 & 0.38 \\
\hline $\begin{array}{c}\text { LMP-4 } \\
3.1 / 1.8\end{array}$ & $\begin{array}{c}4.85 / 2.8 \\
0\end{array}$ & 18.0 & 172.0 & 4.5 & $570 / 235$ & 2.06 & 1.08 \\
\hline $\begin{array}{c}\text { LMP-5 } \\
\text { without } \\
\text { body } \\
\text { frame }\end{array}$ & $\begin{array}{c}2.7 / 0.8 \\
5\end{array}$ & $1.62 / 0.4$ & 32.0 & 94.0 & 2.0 & $370 / 157$ & 1.44 & 0.81 \\
\hline
\end{tabular}

The results of catchers with the parallel connection of magnets experimental studies showed their good convergence with the theoretical data (the difference is 5-15\%). This confirms the validity of the proposed method of the calculation and allows to recommend it for the power magnetic devices based on permanent magnets designing. 
Summing up the results of the catchers with the parallel connection of magnets studies, it can be concluded that the catchers with U-shaped shielded systems on rare earth magnets and especially with the use of magnetic cores and step-shaped magnets have sufficiently high parameters that allow them to be used effectively in wells. U-shaped magnetic systems can also be successfully used in other fields of technology, where operating conditions do not require the use of shielding.

\section{References}

1. H. Polinder, F. F. A. van der Pijl, G.-J. de Vilder, IEEE Trans. Energy Convers., 21:3, pp. 725 (2006)

2. E. P. Furlani, IEEE Trans, Magn., 33:3, 2317 (1997)

3. K. Atallah and D Howe, IEEE Trans. Magn., 37:4, 2844 (2001)

4. K. Atallah, S. D. Calverley, and D. Howe, J. Magn. Magn. Mater., 272:1, 1727 (2004)

5. K. Atallah, S. D. Calverley, and D. Howe, Inst. Electr. Eng. Proc. Electr. Power Appl., 151:2, 135 (2004)

6. P. O. Rasmussen, T. O. Andersen, F. T. Jorgensen, and O. Nielsen, IEEE Trans. Ind. Appl., 41:3, 764 (2005)

7. S. Mezani, K. Atallah, and D. Howe, J Appl. Phys., 99, 08R303-1 (2006)

8. K. Atallah, J. Wang, and D. Howe, J. Appl. Phys., 97, 10N516-1 (2006)

9. K. Atallah, J. Wang, S. Mezani, and Dowe, Inst. Electr. Eng. J. Ind. Appl., 126:10, 1352 (2006)

10. Z. Q. Zhu and D. Howe, Inst. Electr. Eng. Proc. Electr. Power Appl., 148:4, 299 (2001)

11. B. Proca, A. Keyhani, A. EL-Antably, W Lu, and M Dai, IEEE Trans. Energy Convers., 18:3, $386(2003)$

12. Z. P. Xia, Z. Q. Zhu, and D. Howe, IEEE Trans. Magn., 40:4, 1864 (2004)

13. D. Zarko, D. Ban, and T. A. Lipo, IEEE Trans. Magn., 42:7, 1828 (2006)

14. C. C. Mi, G. R. Slemon, and R. Bonert, IEEE Trans. Energy Convers., 20:1, 121 (2005) 